East African Medical Journal Vol. 79 No. + April 2002

UTILISATION OF ANTENATAL AND MATERNITY SERVICES BY MOTHERS SEEKING CHILD WELFARE SER VICES IN MBEERE DISTRICT, KENYA P. K. Mwaniki, KRCHN/DAN, MPH student. Kellyatta University, E. W. Kabiru, Msc. PhD. Senior Lecturer, Department of Zowlogy, Kenyatta University P. O. Box 4.384t. Nairobi, G. G. Mbugua, MBBS, MPH. PHD. Principal Research Officer, Centre for Microbiology Research. Kenya Medical Research Institute, P. O. Box 54840, Nairobi.

Request for reprints to: P. K. Mwaniki. Medteal Training College (Embu), P. O. Box 923 Embu, Kenya.

\title{
UTILISATION OF ANTENATAL AND MATERNITY SERVICES BY MOTHERS SEEKING CHILD WELFARE SERVICES IN MBEERE DISTRICT, EASTERN PROVINCE, KENYA
}

\author{
P.K. MWANIKI, E. W. KABIRU and G.G MBUGUA
}

\begin{abstract}
Background: Utilisation of antenatal and maternity services is an important maternal $I$ ealth indicator. Increasing the proportion of mothers who are cared for in health facilities during pregnancy, childbirth and puerperium reduces the health risks to mothers and their children.

Objective: To determine the utilisation of antenatal and maternity services by mothers of Mbeere District bringing their children to the child welfare clinic.

Design: Cross-sectional, descriptive study.

Setting: Four rural health centres in Mbeere district.

Subjects: Two hundred mothers bringing their children aged one year and below to the child welfare clinic between September and December 2000.

Results: The proportion of mothers who utilised health facilities for antenatal and maternity services was $\mathbf{9 7 . 5 \%}$ and $\mathbf{5 2 \%}$, respectively. Utilisation of health facilities for maternity services was significantly influenced by number of children and distance to health facility in that, as number of children increased, utilisation of maternity services reduced $\left(\chi^{2}=8.99\right.$; $p=0.027 ; d f=1)$. Mothers living less than $5 \mathrm{~km}$ to a health facility utilised the services better than those living $5 \mathrm{~km}$ and beyond $\left(\chi^{2}=7.57 ; \mathrm{p}=0.0059 ; \mathrm{df}=1\right)$. Among the reasons given by the mothers (individual respondents and through Focus Group Discussions) regarding dissatisfaction with the services offered included shortage of drugs and essential supplies, lack of commitment by staff, poor quality of food and lack of cleanliness in the health facilities.

Conclusion: Coverage for antenatal services was high among mothers during their last pregnancy. However, only about half of the mothers interviewed utilised health facilities for maternity services (labour and delivery). The major constraints experienced by the mothers as they sought for the services (as reported by individual respondents and through Focus Group Discussions) included lack of transport, lack of money for transport and hospital fee and delay in admission to health facility once mothers report in labour. Lack of satisfaction with quality of care given could be the major demotivating factor in the use of health facilities for maternity services.
\end{abstract}

\section{INTRODUCTION}

Pregnancy is a special event and pregnant women should be treated with special care. Recognition of the need for Maternal Health Care is spelt out in Article 25-2 of the Universal Declaration of Human Rights as proclaimed in the General Assembly of United Nations on the 10th December 1948.

Antenatal services are services given to a woman by skilled personnel for reasons related to pregnancy. They are aimed at improving the outcome of pregnancy and are more effective when sought early in pregnancy. World Health Organisation (WHO) recommends that the visits are made monthly upto the 28 th week, fortnightly upto the 36 th week and weekly until delivery. This optimum schedule translates into twelve to thirteen visits if first visit is done at the third month of gestation. Reduction in maternal and infant morbidity and mortality rates in England (1) and United States(2) have been attributed to good antenatal care. High maternal mortality has been associated with low quality of antenatal care(3). Babies born to women who receive no antenatal care are three times likely to die in infancy (4). The risk of having a low birth weight infant is three times as high for women with no antenatal care than for those who receive antenatal care(5). In developing countries, only $65 \%$ of women receive adequate antenatalcare(6). According to the Kenya Demographic and Health Survey of $1998,40 \%$ of women had not made any antenatal visit by the start of the sixth month of pregnancy. 
Maternity services are services given to a mother by a skilled personnel during labour, childbirth and puerperium. Professional care at this time is essential for making motherhood safer. However, only $53 \%$ of deliveries in developing countries take place with the assistance of a professional birth attendant and less than $30 \%$ receive postpartum care(6). In Kenya, only $42 \%$ of women were delivered in health facilities between 1995 and 1997(7) and the maternal mortality rate is estimated at 670 per 100,000 livebirths $(8)$.

This study was designed to assess utilisation of antenatal and maternity services by mothers of Mbeere District. Its aim was to determine the proportion of mothers who utilised these services during their last pregnancy, the relationships of selected socio-demographic and accessibility factors with utilization of the services and the perception of mothers regarding quality of the services offered in the health facilities.

\section{MATERIALS AND METHODS}

This was a cross-sectional descriptive survey, whose study population comprised mothers bringing their children to the child welfare clinics. Both cluster and systematic sampling procedures were used. All four rural health centres, that is, Siakago. Kiritiri, Kiambere and Gategi were identified as the clusters. In each cluster, respondents were identified systematically from the service delivery point on random visiting days. The general statistical law of small numbers, which states that as ' $n$ ' approaches infinity, obscrvations $\geq 30$ approach normal distribution was considered. Fifty mothers were interviewed from each of the clusters. Theretore, a total of 200 respondents were included in the study.

Primary data were collected from respondents through personal interviews using a structured questionnaire. Additional qualitative data were obtained through Focus Group Discussions (FGD's) with a group of mothers in each cluster. Data were analysed by use of SPSS computer package and the results were presented in descriptive and inferential methods.

\section{RESULTS}

Socio-demographic characteristics of study population (Table I): Two hundred mothers were interviewed. Their ages ranged between $16-47$ years and the mean age was 25.92 years. Thirty nine percent were in the age bracket of 21-25 years. Eighty three per cent of the mothers were married and $32.0 \%$ were Anglicans. Only $0.5 \%$ had no religious affiliation.

Majority of mothers (77.0\%) had between one to three children. In regard to level of education, $77.0 \%$ had primary level education and only $2.0 \%$ had post secondary education. A large proportion of the mothers (66.0\%) were peasant farmers.

Accessibility parameters (Table 2): Majority of the mothers (76\%) walked to the health facility. Most of them $(71.5 \%)$ took at most two hours to reach the health facility while the rest took more than iwo hours. Only $45 \%$ of the mothers lived less than five kilometres to a health facility.
Table 1

Distribution of all subjects according to selected socio-demographic characteristics of study population $(n=200)$

\begin{tabular}{|c|c|c|c|}
\hline Characteristic & $\begin{array}{r}\text { No. of } \\
\text { subjects }\end{array}$ & $\%$ & \\
\hline \multicolumn{4}{|l|}{ Marital status } \\
\hline Married & 166 & 83.0 & \\
\hline Single & 29 & 14.5 & \\
\hline Separated & 3 & 1.5 & \\
\hline Widowed & 2 & 1.0 & \\
\hline \multicolumn{4}{|l|}{ Religious denomination } \\
\hline Anglican & 64 & 32.0 & \\
\hline Catholic & 59 & 29.5 & \\
\hline Pentecostal & 42 & 21.0 & \\
\hline Apostolic & 23 & 11.5 & \\
\hline Salvation Army & 6 & 3.0 & \\
\hline Independent & 4 & 2.0 & \\
\hline Seventh day & 1 & 0.5 & \\
\hline None & 1 & 0.5 & \\
\hline \multicolumn{4}{|l|}{ Age (years) } \\
\hline$\leq 20$ & 31 & 15.5 & \\
\hline $21-25$ & 78 & 39.0 & Range $16-47$ years \\
\hline $26-30$ & .59 & 29.5 & \\
\hline $31-35$ & 20 & 10.0 & Mean age $25.92 \pm 5.32$ \\
\hline $36-40$ & 9 & 4.5 & \\
\hline $41-45$ & 2 & 1.0 & \\
\hline$\geq 46$ & 1 & 0.5 & \\
\hline \multicolumn{4}{|l|}{ Number of children } \\
\hline $1-3$ & 154 & 77.0 & \\
\hline $4-6$ & 37 & 18.5 & \\
\hline 7.9 & 8 & 14.0 & \\
\hline$\geq 10$ & 1 & 0.5 & \\
\hline \multicolumn{4}{|l|}{ Level of edication } \\
\hline None & 5 & 25 & \\
\hline Primary & 154 & 77.0 & \\
\hline Secondary & 37 & 18.5 & \\
\hline Post-secondary & 4 & 2.0 & \\
\hline \multicolumn{4}{|l|}{ Occupation } \\
\hline Skilled worker & 13 & 6.5 & \\
\hline Unskilled worker & 18 & 9.0 & \\
\hline Peasant farmer & 132 & 66.0 & \\
\hline Housewife & 37 & 18.5 & \\
\hline
\end{tabular}

Table 2

Distribution of subjects according to selected accessibility parameters to a health facility providing antenatal and maternity services $(n=200)$

\begin{tabular}{lrr}
\hline & No. of subjects & \\
Parameter & & \\
\hline $\begin{array}{l}\text { Distance to health facility }(k m) \\
<5\end{array}$ & 90 & 45.0 \\
$5-10$ & 61 & 30.5 \\
$>10$ & 49 & 24.5 \\
Time taken (hours) & 143 & \\
At most 2 & 31 & 71.5 \\
$2.1-3.0$ & 22 & 15.5 \\
$3.1-4.0$ & 4 & 11.0 \\
$\geq 4.1$ & & 2.0 \\
Mode of transport & 152 & 76.0 \\
Walking & 3 & 1.5 \\
Bicycle & 45 & 22.5 \\
Public service vehicle & & \\
\hline
\end{tabular}


Utilisation of antenatal scrvices (Tables 3 and 4): Out of the 200 mothers interviewed, $97.5 \%$ attended antenatal clinic at least once during their last pregnancy. Most of those who attended the clinic $(55.38 \%)$ utilised a government health centre and majority of them did their first visit at between five to seven months gestation. The mean gestation age at first visit was 5.53 months.

Table 3

Distribution of subjects who attended amtenatal clinic according to type of health facilitw risited

\begin{tabular}{lrr}
\hline Health facility & No. of subjects & $\%$ \\
\hline Government health centre & 108 & 55.38 \\
Government hospital & 16 & 8.21 \\
Mission hospital & 2 & 1.03 \\
Government dispensary & 59 & 30.26 \\
Private clinic & 5 & 2.56 \\
Outreach service & 5 & 2.56 \\
& & 195 \\
\hline Total & & 100.00 \\
\hline
\end{tabular}

Table 4

Distribution of subjects who attended antenatal clinic according to gestation age at first lisit

\begin{tabular}{|c|c|c|c|}
\hline $\begin{array}{l}\text { Gestation age } \\
\text { (months) }\end{array}$ & $\begin{array}{l}\text { No. of } \\
\text { subjects }\end{array}$ & $\%$ & \\
\hline $1-3.0$ & 1 & 0.5 & \\
\hline $3.1-5.0$ & 45 & 23.1 & \\
\hline $5.1-7.0$ & 106 & 54.4 & Mean $5.53 \pm 1.28$ \\
\hline$\geq 7$ & 43 & 22.0 & \\
\hline Total & 195 & 100.0 & \\
\hline
\end{tabular}

Utilisation of maternity services (Tables 5 and 6): One hundred and four mothers $(52.0 \%)$ utilised health facilities during labour and delivery. For those who did not utilise health facilities, $81(40.5 \%)$ delivered at home while $15(7.5 \%)$ delivered on the way to a health facility. Out of those who delivered in a health facility, $41.3 \%$ utilised a Government hospital and the same percentage utilised a Government health centre. Only $51.0 \%$ of deliveries were conducted by a health worker.

Table 5

Distribution of subjects who utilised matemily services according to type of health facility attended

\begin{tabular}{lrr}
\hline Type of health facility & $\begin{array}{r}\text { No. of } \\
\text { subjects }\end{array}$ & $\%$ \\
\hline Government hospital & 43 & 41.3 \\
Government health centre & 43 & 41.3 \\
Mission hospital & 14 & 13.5 \\
Private clinic & 4 & 3.9 \\
\hline & 104 & 100.0 \\
\hline
\end{tabular}

Table 6

Distribution of subjects corcording to who attended the delivery

\begin{tabular}{lrr}
\hline Attendant at birth & $\begin{array}{r}\text { No. of } \\
\text { subjects }\end{array}$ & $\%$ \\
\hline Self & 13 & 6.5 \\
Family member/neighbour & 65 & 32.5 \\
Traditional birth attendant & 20 & 10.0 \\
Health worker. & 102 & 51.0 \\
\hline Total & 200 & 100.0 \\
\hline
\end{tabular}

Analytical results: Results of cross-tabulations for selected socio-demographic and acces ibility variables against utilisation of services revealed that use of maternity services was significantly influenced by number of children a mother had, age of mother and distance to health facility as follows: (i) as number of children increased, utilisation of maternity services reduced $\left(\chi^{2}=8.99 ; p=0.0027 ; \mathrm{df}=1\right)$; (ii) mothers living less than $5 \mathrm{~km}$ to a health facility utilised maternity services better than those living $5 \mathrm{~km}$ and beyond $\left(\chi^{2}=7.57 ; \mathrm{p}=0.0059 ; \mathrm{df}=1\right)$; (iii) there was a negative correlation between mothers age and hospital delivery in that, as mothers advance in age, they delivered at home more and; (iv) utilisation of post-natal services was better in mothers with three children and below compared to those with more than three children.

\section{DISCUSSION}

In this study, analysis of results showed that utilisation of antenatal services amongst mothers seeking child welfare services was high. One hundred and ninety five $(97.5 \%)$ of the mothers attended antenatal clinic at least once during their last pregnancy. The modal gestation age at first visit was between five to seven months with a mean of 5.53 months. The results revealed that there is a general motivation to attend antenatal clinic and that there exists an opportunity for the health workers to encourage early and more frequent visits. These results are backed up by those of the Kenya Demographic and Health Survey of 1998, which showed that antenatal clinic attendance stood at $92 \%$ with a mean gestation age at first visit of 5.7 months.

Other studies have shown the attendance to antenatal clinic to be quite good, but a number of these studies did not establish how many times the antenatal clinic was attended per pregnancy $(9-11)$. Ngoka and Mati in 1980 reported that most mothers attended antenatal clinic only a few times and often started late in pregnancy hence diluting the effect of the antenatal care(12). The average number of visits per pregnant woman reported in Embu, a district neighbouring Mbeere was 2.1(13).

An important component of efforts to reduce the health risks of mothers and children is increasing the proportion of mothers cared for in health facilities during labour and delivery. Care by trained attendants and hygienic conditions during delivery can reduce risks of 
complications and infections that can cause death or serious illness either of mother or baby. This study revealed that $104.52 \%$ ) of mothers delivered in a health facility during their last pregnancy. Eight-one $(40.5 \%)$ delivered at home while fifteen $(7.5 \%)$ delivered on the way to a health facility. Further analysis in respect of attendant at birth showed that $102(51 \%)$ of mothers were attended by health workers, sixty five $(32.5 \%)$ by family member neighbour, twenty $(10 \%)$ by traditional birth attendant while thirteen $(6.5 \%)$ gave birth without assistance.

The reasons given by individual respondents and through Focus Group Discussiofss regarding dissatisfaction with quality of maternity care included shortage of drugs and essential supplies, unfriendly staff who were not committed to their work, poor quality and inadequate quantity of food and lack of cleanliness in health facilities. They also reported common obstacles encountered in the course of seeking for maternity services which included lack of transport to reach health lacility, delay in admission to health facility once mothers report in labour and lack of money for transport and hospital fee.

The mothers suggested that drugs and essential șpplies be made available in the health facilities health workers be more friendly and committed to their work, and those mothers reporting to a health facility in labour pains be admitted irrespective of the slage of labour. Other suggestions made were that the quality and quantity of food provided especially to post-natal mothers be improved, cost sharing lee be reduced to make services affordable (and those unable to pay not to be denied (he services). They also suggested that additional nurses should be deployed where there are shortages, additional beds and linen to be provided to avoid sharing of heds in matcrnity. cleanliness in health facilities to be improved, all health facilities to have laboratory services and antenatal and maternity services to be brought nearer where mothers live.

The results of this study are consistent with findings elsewhere. Estimates around the world show that only some $57 \%$ of the births are attended by trained personnel and even fewer take place in a health institution. In the developing world, the highest coverage is in Eastem Asia with uniformly high levels in all countries. The only notable exceptions are the rural areas of the Republic of Korea. Some of the world's lowest rates are found in South Asia including the rural areas of Afghanistan, Bangladesh. Nepal and Yemen. In Africa, the coverage is uniformly low with country values ranging from as low as two per cent in Somalia(14).

In Kenya, the trend of health lacilities for labour and delivery services has been on the decline. The 1993 Kenya Demographic and Health Survey. for example, found that $44 \%$ of pregnant women delivered in a health facility while $56 \%$ delivered at home. Of those who delivered at home, nearly half were assisted by a TBA (trained and untrained), nearly the same proportion received care froin a relative while a few women delivered without assistance at all(15). The findings of the 1994 Baseline Maternal Mortality Survey found that about one-half of all births took place in a health facility (16) and in 1998, the Kenya Demographic: and Health Survey revealed that only $42 \%$ of births were delivered in health facilities between 1995 and 1997(7).

In conclusion, women's use of health services is greatly influenced by their expectations of those services and whether those expectations are met. The jquality of care is more important than the number of times a client is seen in the health facility. If pregnant women get even the most simple, basic, cheap but quality antenatal and maternity care, it can make their pregnancy and birth much safer and play a significant role in reducing maternal morbidity and mortality. In order to increase coverage and improve the quality of maternity services, health managers and administrators should devise ways of strengthening the capacity of health facilities to provide essential antenatal and maternity. services by addressing the reasons given by the mothers that cause dissatisfaction with the services offered. Staff working in the health facilities should have frequent continuing education sessions in order to improve their sensitivity to the needs of the patients/clients. Community oriented activities can also be initiated in order to enhance coverage. This can include communitybased education programmes and provision of eare where mothers congregate like in churches, markets and women meetings. Further resejarch work is however, required to determine whether there are any cultural factors that hinder utilisation of the services. There is also need to seek the perspectives of the health care providers at the operational level on how the services can be improved.

\section{REFERENCES}

1. Loudon I. On matemal and infant mortality. Society for the Social History of Medicine. 1991.

2. Maine D. Safe motherhood Programs: Options and Issues. New York: Columbia University, 1991.

3. Filipi G.G. Graham, W.J. and Campbell O.M. Utilising survey data on maternity care in developing countries. Maternal and child epidemiology unit. Publication No. 3, London: London School of Hygiene and Tropical Medicine. 1990.

4. Hugh's D. The health of America's children: Maternal and child. healthdata book. Washington DC: Children's Defense Fund. 1986

5. Institute of Medicine. Preventing low bith weight. Washington DC: National Academy Press, 1985.

6. World Health Organisation. Coverage of Maternal care: A listing of available infomation (in press), Geneva, 1997.

7. Kenya Demographic and Health Survey (KDHS, 1998).

8. World Health Organisation. Revised 1990 estimates of maternal mortality: A new approach by WHO and UNICEF. Geneva, 1996.

9. Mati, J.K., Aggarwal, V.P. and Lecas. The Nainobi birth survey IV Early perinatal mortality rate. J. Obst. Gym. East Cent Aff 1983 2: $129-13.3$.

10. Were'E. Stillbirths at Eldoret District Hospital: A retrospective study. East Afr: Med. J. 1994:71:609-610.

11 Were, E.O. and Karanja J.K. Low bith weight deliveries at the New Nyanza General Hospital. Kisumu, Kenya. Eust Afi. Med. I. 1994: 71:667-670.

12. Ngoka, W.M. andMati,J.K.Obstetricaspect of adolescent pregnancy at Kenyatta National Hospital. Eatst Afr. Med.J. 1980:57.124.130

13. Ministry of Health. Annual Health Report. Fmbu District: Health Information Systems (HIS), 1993..

14. World Health Organisation. Coverage of maternity care: A tabulation of available information. Division of Fanvily Heath? Geneva, 1989.

15. Kenya Demographic and Health Survey (KDHS, 1993).

16. Kenya Maternal Mortality Baseline Survey. 1994: Vol. 11, 1996. 